\title{
Inhibitory avoidance learning in young rats effected by previous familiarization with the apparatus
}

\author{
ROBERT A. JENSEN and JOEL L. DAVIS \\ Northern Illinois University, DeKalb, Illinois 60115
}

\begin{abstract}
Male rats $18,21,25$, and 100 days of age were trained in a one-trial passive avoidance paradigm, in which size of the apparatus was matched to the age of the rats. They were tested $24 \mathrm{~h}$ later. Older animals displayed increased retention, and familiarization training facilitated performance in the 21- and 25-day-old rats, but not in the 18- and 100-day-old rats. This indicates that a component of the passive avoidance deficit seen in young animals may relate to a difficulty in associating stimulus cues with a learning situation.
\end{abstract}

In recent years, a number of studies have investigated ontogenetic differences between young and older animals in their capacities to learn avoidance responses. In these studies, young animals have generally been shown to learn an active avoidance response with an efficiency approaching or equaling that demonstrated by older animals. This has been demonstrated in rats by Kirby (1963), who reported that in a runway situation, there were no significant differences in acquisition or extinction of an avoidance response in 25-, 50-, and 100-day-old rats. Similar results have been reported in a number of other studies as well (Campbell, 1967; Denenberg \& Kline, 1958; Riccio, Rohrbaugh, \& Hodges, 1968). Species such as monkeys (Mason \& Harlow, 1958), chicks (Peters \& Isaacson, 1963), and domestic cats (Davis \& Jensen, 1976) also show effective active avoidance learning at young ages.

In each of these experiments, though, the animal was required to make a response-to do something-in order to avoid punishment. In inhibitory avoidance situations where the animal is required to withhold a response in order to avoid punishment, the data reflect some sort of ontogenetic differences between immature and adult subjects. Despite the fact that inhibitory avoidance learning is particularly well suited to immature animals because the correct response consists of staying in one place, and thus one cannot attribute any learning deficit in the younger animals to locomotor impairment, a number of studies (Egger \& Livesey, 1972; Feigley \& Spear, 1970; Riccio et al., 1968; Schulenberg, Riccio, \& Stikes, 1971) with rats have shown that performance of young animals is substantially poorer in young animals. This finding

The research presented here was supported by Research Grant HD NS 07054-02. Robert A. Jensen is now at the Department of Psychobiology, University of California, Irvine, California 92717. Joel L. Davis is now at the Psychobiology Research Laboratory, Veterans Administration Hospital, Sepulveda, California 91343. has also been verified in 25-day-old kittens (Davis \& Jensen, 1975).

It is likely that inhibitory avoidance learning involves two states: (1) the acquisition of fear associated with the instrumental cues of stepping into the forbidden place and classical association with the stimulus cues of that situation, and (2) inhibiting the response. Thus, the deficit that young animals show in inhibitory avoidance situations can be viewed in one of two ways: either as a failure of acquisition, that is, the young animal simply does not learn to fear the environmental and response produced stimuli; or as a lack of inhibitory mechanisms in the immature animals. The aim of this research is to determine which of these possible explanations of the deficits observed in young animals is the more useful.

To test for the possible contributions of a deficit in inhibition and a deficit in learning in young animals, we employed preexposure to the apparatus before the training trial. This preexposure, or familiarization (FAM) has been demonstrated to both increase the efficiency of inhibitory avoidance learning (King \& Glasser, 1973) and attenuate the amount of amnesia seen after amnestic treatments such as ECS or hypothermia (Jensen \& Riccio, 1970; Lewis, Miller, \& Misanin, 1968). It has been argued that the FAM effect depends on the exposure to specific apparatus cues, and this preexposure increases the discriminability of the situation and results in improved learning. If this is the case, and if the inhibitory avoidance deficit in young animals is due to difficulties in learning, then a FAM trial prior to the training trial might be expected to improve retention performance. On the other hand, if the deficit is due to a limited ability to inhibit, then the FAM trial may be expected to have less effect.

\section{METHOD}

\section{Subjects}

One hundred and fifty-five male rats of the Wistar strain 
born and bred in the Northern Illinois University Psychology Department animal colony were employed in this experiment.

\section{Procedure}

On the day of birth, the pups were sexed and male pups were marked by placing a small dye injection in the right front paw. Female rats were not used in this study. The pups then remained undisturbed except for normal cage maintenance until use in the experiment. Thirty-nine rats were trained at 18 days of age, 42 on Day 21, 36 on Day 25, and 30 at 100 days of age. Young rats were trained in a two-chamber black-andwhite box that measured $22.0 \times 14.5 \times 17.0 \mathrm{~cm}$, while the 100-day-old rats were trained in a similar but larger apparatus that measured $30 \times 20 \times 20 \mathrm{~cm}$. The younger animals were trained in the smaller apparatus since size of the apparatus may contribute to the observed deficit in inhibitory avoidance performance seen in young animals (Feigly \& Spear, 1970). On the day preceding training, approximately one-half the animals in each group were allowed to explore the apparatus for $5 \mathrm{~min}$. The other animals were each placed in a clear acrylic cage pan for $5 \mathrm{~min}$. On the day of training, each rat was placed in the white side of the apparatus facing away from the guillotine door, and $20 \mathrm{sec}$ later the door was opened. Latency to cross through into the dark chamber was recorded. Upon entry, the door was closed and a 1-sec 1-mA scrambled shock was given. Each rat was then removed and returned to its home cage. The rats were tested $24 \mathrm{~h}$ later; the procedure was the same as the training procedure except that no shock was given.

\section{Results}

The median entrance latencies of the 18-day-old rats trained after familiarization with the apparatus was $13.4 \mathrm{sec}$, while that of those trained without familiarization was $19.9 \mathrm{sec}(\mathrm{U}=181$, n.s.) (see Figure 1). In the rats trained at 21 and 25 days of age, significant differences were observed (21-day-old rats: $F A M=217 \mathrm{sec}$, non-FAM $=45 \mathrm{sec}, \mathrm{U}=105.5, \mathrm{p}<.01 ; 25$-day-old rats: $\mathrm{FAM}=310.5 \mathrm{sec}$, non-FAM $=87 \mathrm{sec}, \mathrm{U}=73, \mathrm{p}<.01$ ). In the rats trained at 100 days of age, no significant differences were observed between the latencies of the groups $(\mathrm{FAM}=600 \mathrm{sec}$, non-FAM $=513 \mathrm{sec}, \mathrm{U}=149.5$, $\mathrm{p}>.10)$.

These data demonstrate that the opportunity to explore the apparatus on the day prior to training facilitated performance in the 21- and 25-day-old rats. Therefore, part of the deficit seen in the 21- and 25-dayold rats as compared to mature animals may be caused by deficiencies in the ability to associate a particular place with punishment. Since both groups of 18-day-old animals showed poor performance on the test day, the observed deficit may be mediated both by an inability to learn and difficulty in inhibiting activity.

\section{REFERENCES}

CAMPBell, B. A. Learning in infra-primate mammals. In H. W. Stevenson, E. H. Hess, \& H. L. Rheingold (Eds.), Early behavior. New York: Wiley, 1967.

DAvis, J. L., \& Jensen, R. A. Developmental aspects of active and passive avoidance learning in the cat. Developmental Psychobiology, 1976, 5, 175-179.

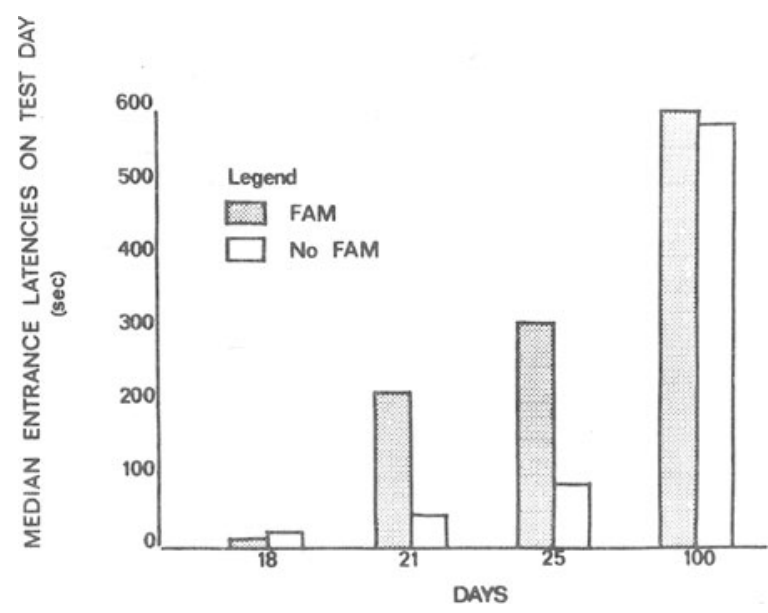

Figure 1. Median entrance latencies on test day for rats trained with or without familiarization.

Denenberg, V. H., \& Kline, N. J. The relationship between age and avoidance learning in the hooded rat. Journal of Comparative and Physiological Psychology, 1958, 51, 488-492.

Egger, G. J., \& Livesey, P. J. Age effects in the acquisition and retention of active and passive avoidance learning by rats. Developmental Psychobiology, 1972, 5, 343-351.

Feigley, D. A., \& SPEAR, N. E. Effect of age and punishment conditions on long term retention by the rat of activeand passive-avoidance learning. Journal of Comparative and Physiological Psychology, 1970, 73, 515-526.

JENSEN, R. A., \& Riccio, D. C. Effects of prior experience upon retrograde amnesia produced by hypothermia. Physiology and Behavior, 1970, 5, 1291-1294.

KING, R. A., \& Glasser, R. L. Factors influencing one-trial passive avoidance behavior: Implications for studies of retrograde amnesia (RA). Physiology and Behavior, 1973, 10, 817-819.

KIRBY, R. H. Acquisition, extinction, and retention of an avoidance response in rats as a function of age. Journal of Comparative and Physiological Psychology, 1963, 56, 158-162.

Lewis, D. J., Miller, R. R., \& Misanin, J. R. Control of retrograde amnesia. Journal of Comparative and Physiological Psychology, 1968, 66, 48-52.

MASON, W. A., \& HaRLow, H. F. Formation of conditioned responses in infant monkeys. Journal of Comparative and Physiological Psychology, 1958, 51, 68-70.

Peters, J., \& Is ancson, R. Acquisition of active and passive responses in two breeds of chickens. Journal of Comparative and Physiological Psychology, 1963, 56, 793-796.

Riccio, D. C., Rohrbaugh, M., \& Hodges, L. A. Developmental aspects of passive and active avoidance learning in rats. Developmental Psychobiology, 1968, 1, 108-111.

Schulenburg, C. J., Riccio, D. C., \& Stikes, E. R. Acquisition and retention of a passive-avoidance response as a function of age in rats. Journal of Comparative and Physiological Psychology, 1971, 74, 75-83.

(Received for publication January 5, 1978.) 